\title{
Article \\ Room Temperature Deposition of Nanocrystalline SiC Thin Films by DCMS/HiPIMS Co-Sputtering Technique
}

\author{
Vasile Tiron $^{1}$, Elena-Laura Ursu ${ }^{2}$, Daniel Cristea ${ }^{3, *(\mathbb{D})}$, Georgiana Bulai ${ }^{4} \mathbb{D}^{\text {, }}$, George Stoian ${ }^{5}$, , Teodora Matei ${ }^{6}$ \\ and Ioana-Laura Velicu $6, *$ [D
}

1 Department of Exact and Natural Sciences, Research Center on Advanced Materials and Technologies (RAMTECH), Institute of Interdisciplinary Research, Alexandru Ioan Cuza University of Iasi, 700506 Iasi, Romania; vasile.tiron@uaic.ro

2 Centre of Advanced Research in Bionanoconjugates and Biopolymers, Petru Poni Institute of Macromolecular Chemistry, 700487 Iasi, Romania; ursu.laura@icmpp.ro

3 Department of Materials Science, Faculty of Materials Science and Engineering, Transilvania University, 500068 Brasov, Romania

4 Science Department, Integrated Center of Environmental Science Studies in the North-Eastern Development Region (CERNESIM), Institute of Interdisciplinary Research, Alexandru Ioan Cuza University of Iasi, 700506 Iasi, Romania; georgiana.bulai@uaic.ro

5 National Institute of Research and Development for Technical Physics, 700050 Iasi, Romania; gstoian@phys-iasi.ro

6 Faculty of Physics, Alexandru Ioan Cuza University of Iasi, 700506 Iasi, Romania; dorateom@yahoo.com

* Correspondence: daniel.cristea@unitbv.ro (D.C.); laura.velicu@uaic.ro (I.-L.V.)

\section{check for}

updates

Citation: Tiron, V.; Ursu, E.-L.; Cristea, D.; Bulai, G.; Stoian, G.; Matei, T.; Velicu, I.-L. Room Temperature Deposition of Nanocrystalline SiC Thin Films by DCMS/HiPIMS Co-Sputtering Technique. Nanomaterials 2022, 12, 512. https://doi.org/10.3390/ nano12030512

Academic Editor: Christophe Detavernier

Received: 13 December 2021

Accepted: 28 January 2022

Published: 1 February 2022

Publisher's Note: MDPI stays neutral with regard to jurisdictional claims in published maps and institutional affiliations.

Copyright: (c) 2022 by the authors. Licensee MDPI, Basel, Switzerland. This article is an open access article distributed under the terms and conditions of the Creative Commons Attribution (CC BY) license (https:/ / creativecommons.org/licenses/by/ $4.0 /)$.

\begin{abstract}
Due to an attractive combination of chemical and physical properties, silicon carbide ( $\mathrm{SiC}$ ) thin films are excellent candidates for coatings to be used in harsh environment applications or as protective coatings in heat exchanger applications. This work reports the deposition of nearstoichiometric and nanocrystalline $\mathrm{SiC}$ thin films, at room temperature, on silicon (100) substrates using a DCMS/HiPIMS co-sputtering technique (DCMS-direct current magnetron sputtering; HiPIMS-high-power impulse magnetron sputtering). Their structural and mechanical properties were analyzed as a function of the process gas pressure. The correlation between the films' microstructure and their mechanical properties was thoroughly investigated. The microstructure and morphology of these films were examined by appropriate microscopic and spectroscopic methods: atomic force microscopy (AFM), scanning electron microscopy (SEM), energy-dispersive X-ray spectroscopy (EDX), X-ray diffraction (XRD), and Raman spectroscopy, while their mechanical and tribological properties were evaluated by instrumented indentation and micro-scratch techniques. The lowest value of the working gas pressure resulted in SiC films of high crystallinity, as well as in an improvement in their mechanical performances. Both hardness $(\mathrm{H})$ and Young's modulus (E) values were observed to be significantly influenced by the sputtering gas pressure. Decreasing the gas pressure from 2.0 to 0.5 Pa led to an increase in $\mathrm{H}$ and $\mathrm{E}$ values from 8.2 to $20.7 \mathrm{GPa}$ and from 106.3 to $240.0 \mathrm{GPa}$, respectively. Both the $\mathrm{H} / \mathrm{E}$ ratio and critical adhesion load values follow the same trend and increase from 0.077 to 0.086 and from 1.55 to $3.85 \mathrm{~N}$, respectively.
\end{abstract}

Keywords: DCMS/HiPIMS co-sputtering; nanocrystalline silicon carbide; coating; hardness; adhesion

\section{Introduction}

Silicon carbide $(\mathrm{SiC})$ is a semiconductor composed of light elements. Due to its attractive properties, including its low coefficient of thermal expansion, low neutron absorption cross-section, high thermal conductivity, high hardness, and superior tribological, chemical and oxidation resistance, it is well suited as a protective coating in heat exchanger applications [1] or as a sensing material in harsh environments [2,3]. Due to their chemical inertness, SiC-based thin films have great potential as protective layers for Si-based 
micro-electro-mechanical systems (MEMS) [4,5], coatings for biomedical applications [6], passivation coatings on metallic materials [7], or barrier layers for solar cells [8].

Silicon carbide is also characterized by a relatively wide bandgap, high electron saturated drift velocity, high breakdown field, and good thermal conductivity [9], and it is generally used for high-frequency, high-current-power, and high-temperature electronic devices. To obtain chemically resistant diffusion barriers or passivation layers, pinhole-free films characterized by good uniformity and low stress are required. Compared to the most often used deposition techniques (i.e., pulsed laser deposition and chemical vapor deposition), magnetron sputtering has several important advantages, such as its costeffectiveness, simplicity, high deposition rate, low deposition temperature, good adhesion of films to the substrate, excellent uniformity on large-area substrates and the ability to easily control films' stoichiometry $[10,11]$.

Due to a high ionization degree of the sputtered material, the high-power impulse magnetron sputtering (HiPIMS) deposition method has been reported to form smooth, dense, and strongly-adherent materials in the form of thin films/coatings [12-14]. Due to its low duty cycle, HiPIMS can operate under a low average power without compromising the ion-to-neutral flux fraction [15]. This feature recommends using HiPIMS in co-sputtering systems when the stoichiometry of the deposited coatings needs to be tuned with high precision or when dealing with a significant difference between the sputtering yields of the targets. In addition, due to its ability to generate energetic gas and metal ion flux [16], HiPIMS is an efficient tool in co-sputtering systems [17], even when the second magnetron is powered in DC mode [18]. As compared to the DCMS technique, due to a higher ion-toneutral flux ratio and higher kinetic energy of sputtered particles, the coatings deposited by HiPIMS present higher density and demonstrate better adhesion on the substrate. Recently, Galvão et al. have shown that HiPIMS can be used to fabricate nanocrystalline $\mathrm{SiC}$ thin films without heating or biasing the Si substrate by making deposits on top of AlN interlayers [19].

To enhance the long-term performance of surface-engineered systems, the mechanical and tribological parameters (i.e., elastic modulus, hardness, and scratch/wear resistance) need to be optimized by varying the process parameters. Despite the enormous potential of silicon carbide films deposited by physical vapor deposition (PVD) systems, as far as we are aware, there is a general lack of relevant information needed to understand the influence of the working gas pressure on their structural and mechanical properties. For this reason, the influence of the deposition process (i.e., working gas pressure) on the properties of $\mathrm{SiC}$ films must be studied.

Due to the preferential re-sputtering phenomenon of $\mathrm{Si}$ atoms from $\mathrm{SiC}$ films, the stoichiometry cannot be fully transported from the target onto the thin film when a SiC target is sputtered [20]. Consequently, for this work, in order to control the chemical composition of the coatings, silicon carbide films were prepared by the DCMS/HiPIMS co-sputtering technique at room temperature by sputtering graphite and silicon targets in direct current magnetron sputtering (DCMS) and HiPIMS modes, respectively. Although the chemical composition of the $\mathrm{SiC}$ films can be finely tuned by proper adjustment of the average discharge power applied on each target or through the relative position of the magnetrons, this work reports only results on near-stoichiometric $\mathrm{SiC}$ ( $\mathrm{Si} / \mathrm{C}$ atomic ratio of about 1:1).

Hereinafter, the influence of the working gas pressure on the structure, surface morphology, Young's modulus, hardness, critical adhesion loads, and friction coefficient of $\mathrm{SiC}$ thin films obtained by the DCMS/HiPIMS co-sputtering technique will be presented.

\section{Materials and Methods}

\subsection{Sample Preparation}

$\mathrm{SiC}$ thin films (thickness of about $750 \mathrm{~nm}$ ) were deposited on Si (n-type 100) wafers, with a surface area of $20 \times 20 \mathrm{~mm}^{2}$ and thickness of $0.675 \mathrm{~mm}$ at ambient temperature by magnetron co-sputtering of graphite and silicon circular targets $(99.999 \%$ purity, $50 \mathrm{~mm}$ 
in diameter) in DCMS (graphite) and HiPIMS (silicon) modes. The angle between the symmetry axis of each magnetron and the normal to the surface of the deposition substrate was set to 22.5 degrees. Prior to the deposition process, the chamber of the sputtering system was evacuated to a base pressure lower than $10^{-4} \mathrm{~Pa}$ using a system consisting of a turbo-molecular pump and a dry scroll pump. Argon (99.999\% purity) was utilized as a working gas, and it was supplied into the deposition chamber at a constant flow rate of $10 \mathrm{sccm}$.

Throughout the process, the gas pressure was varied from 0.5 to $2.0 \mathrm{~Pa}$ by controlling the valve between the chamber and the turbomolecular pump. The Si substrate was placed $100 \mathrm{~mm}$ away from the targets on the symmetry axis of the whole deposition system. No heating source was connected to the substrate holder during the sputtering process. The chemical composition and deposition rates of the films were calculated based on the calibrations performed for each sputtered target using a quartz crystal microbalance (QCM). By properly adjusting the average power applied on each target, the precise control of the films' composition was obtained, independent of the processing gas pressure. The films' thickness was controlled thanks to in situ monitoring of the deposition rate by the QCM.

The graphite sputtering process was performed in DCMS mode under a constant discharge power of $150 \mathrm{~W}$. The silicon target was sputtered in pre-ionized HiPIMS mode under a constant power of $80 \mathrm{~W}$ using short voltage pulses with an amplitude of $-950 \mathrm{~V}$ and a duration of $10 \mu \mathrm{s}$. An extensive description of the pre-ionized HiPIMS power supply and pre-ionized pulsed mode can be found in one of our previous works [21]. It should be mentioned that by varying the working gas pressure from 0.5 to $2.0 \mathrm{~Pa}$, the peak current on the Si target remains constant at a value of $30 \mathrm{~A}$. For each value of the process pressure, the pulsing frequency was correspondingly varied to preserve the stoichiometry of the deposited SiC films. In addition, to ensure the uniformity of the thickness and stoichiometry, the substrate holder was rotated during the deposition process around its symmetry axis, with a rotation speed of $10 \mathrm{rpm}$. Depending on the background processing gas pressure $(\mathrm{p})$, the deposition rate $(S)$ values ranged from $5.6 \mathrm{~nm} / \mathrm{min}(\mathrm{p}=0.5 \mathrm{~Pa})$ to $1.5 \mathrm{~nm} / \mathrm{min}$ $(\mathrm{p}=2 \mathrm{~Pa})$ (see Table 1). The deposition time was conveniently adjusted to obtain SiC films with a thickness of about $750 \mathrm{~nm}$.

Table 1. Values of deposition rate (S), roughness ( $\left.R_{R M S}\right)$, and atomic concentration of SiC films deposited on Si substrates using different process pressures.

\begin{tabular}{|c|c|c|c|c|c|c|}
\hline Sample & $\mathbf{p}(\mathbf{P a})$ & $\mathrm{S}(\mathrm{nm} / \mathrm{min})$ & $\mathbf{R}_{\mathrm{RMS}^{\mathrm{a}}}(\mathrm{nm})$ & $\mathrm{Si}^{\mathrm{b}}$ (at.\%) & $\mathrm{C}^{\mathrm{b}}$ (at.\%) & $\mathrm{Si} / \mathrm{C}$ \\
\hline SiC_1 & 0.50 & 5.6 & 3.4 & $49 \pm 1$ & $51 \pm 1$ & 0.96 \\
\hline SiC_2 & 0.65 & 4.6 & 4.4 & $49 \pm 1$ & $51 \pm 1$ & 0.96 \\
\hline SiC_3 & 0.80 & 3.4 & 5.0 & $49 \pm 1$ & $51 \pm 1$ & 0.96 \\
\hline $\mathrm{SiC}_{4} 4$ & 1.00 & 3.0 & 5.8 & $49 \pm 1$ & $51 \pm 1$ & 0.96 \\
\hline $\mathrm{SiC}_{5} 5$ & 2.00 & 1.5 & 6.8 & $52 \pm 2$ & $48 \pm 2$ & 1.08 \\
\hline
\end{tabular}

a Referred to in Section 3.1, ${ }^{\mathrm{b}}$ Referred to in Section 3.2.

\subsection{Analytical Techniques}

Atomic force microscopy (AFM) scans were performed with a NT-MDT Solver Pro system (Moscow, Russia) to obtain the morphology and roughness ( $\mathrm{R}_{\mathrm{RMS}}$ parameter) of the deposited SiC films. The surface was scanned in non-contact mode, ex situ, at ambient temperature using the same cantilever (NSC21 from Mikromasch, Tallinn, Estonia) and laser position to allow the qualitative comparison across the investigated samples. For statistical relevance, AFM scans were performed over multiple random $3 \times 3 \mu \mathrm{m}^{2}$ areas. Microscope controlling, image acquisition and data processing were performed using Nova software (version 1.0.26.1443) from NT-MDT.

The chemical composition and microstructure of the obtained $\mathrm{SiC}$ thin films were analyzed with a field-emission scanning electron microscope (NEON 40 EsB/Carl Zeiss AG, Oberkochen, Germany) equipped with an energy dispersive spectroscopy (EDS) detector (X-max from Oxford Instruments, Oxford, UK). Besides the detector, the analysis 
system includes a dedicated computer which acquires and processes the data by means of a dedicated software (INCA Energy Software 350, version 4.15) developed by Oxford Instruments. All the results (elemental analysis, EDS mapping, spectra, etc.) are generated through the INCA Energy software.

To investigate the chemical bonding configuration of the deposited $\mathrm{SiC}$ thin films, micro-Raman measurements were performed using a commercial confocal microscope (Renishaw inVia, Wotton-under-Edge, Gloucestershire, United Kingdom) equipped with a He-Ne laser (excitation wavelength-632.8 nm, beam power-17 $\mathrm{mW}$ ) and a CCD detector coupled to a Leica DM 2500M microscope (Wetzlar, Germany). All the measurements were carried out under ambient laboratory conditions (ambient temperature and atmospheric pressure) in backscattering geometry, with the light being focused and collected through a $50 \times$ objective with a numerical aperture of 0.75 . Spectral data processing was performed with the WiRE 3.2 software (Renishaw, UK).

The structural properties of the SiC thin films were analyzed by X-ray diffraction (XRD) using a Shimadzu LabX XRD-6000 Diffractometer (Kyoto, Japan) with $\mathrm{Cu} \mathrm{K}_{\alpha}$ radiation $(\lambda=1.54059 \AA)$ in Bragg-Brentano configuration. The diffractograms were recorded in the $2 \theta$ range of $10-80$ degrees with a scan speed of $0.6 \mathrm{deg} / \mathrm{min}$.

The mechanical and tribological properties (Young's modulus, E, hardness, $\mathrm{H}$, critical adhesion loads, LC, and coefficient of friction) of SiC films deposited on Si substrates were investigated by instrumented indentation and micro-scratch tests in ambient atmosphere using a nanoindentation tester $\left(\mathrm{NHT}^{2}\right.$, equipped with a three-sided diamond pyramidal Berkovich indenter tip, tip radius of about $100 \mathrm{~nm}$ ) and a micro-scratch tester (MST, equipped with a diamond Rockwell-type indenter, tip radius of about $100 \mu \mathrm{m}$ ) from CSM Instruments / Anton Paar (Peseux, Switzerland). The nanoindentation data was processed using the Oliver\&Pharr model [22]. To minimize the substrate's influence on the indentation data, the maximum load was set in such a way as to limit the indentation depth to no more than $100 \mathrm{~nm}$ (approximately 15\% of the films' thickness). In addition, for statistical relevance, the load-controlled indentations were performed over multiple random areas, and the average values of hardness and Young's modulus were calculated from at least 30 load-displacement curves. During microscratch tests, the load was progressively applied on a length of $3 \mathrm{~mm}$, from $0.03 \mathrm{~N}$ to $10.00 \mathrm{~N}$, with a loading rate of $5 \mathrm{~N} / \mathrm{min}$. The critical load values were determined by microscopic analysis of the residual scratch tracks. The critical load values given for each sample are the average of at least five scratch tracks. These critical adhesion loads are defined as follows: the first critical load ( $\left.\mathrm{LC}_{1}\right)$ - the load necessary for the emergence of the first cracks in the film; the second critical load $\left(\mathrm{LC}_{2}\right)$ - the load corresponding to the first delamination of the film; and the third critical load $\left(\mathrm{LC}_{3}\right)$ - the load necessary for the delamination of more than $50 \%$ of the film from the scratch track. The wear behavior was assessed on the same micro-scratch tester (MST, Anton Paar/CSM Instruments, Peseux, Switzerland) using the following parameters: $\mathrm{Si}_{3} \mathrm{~N}_{4}$ $5 \mathrm{~mm}$ balls as counter friction partner; dry conditions; applied load-1N; linear motion; wear track length $5 \mathrm{~mm}$; stop condition-33 passes. The result of interest was the variation of the dynamic friction coefficient as a function of the pass number.

\section{Results and Discussion}

\subsection{Surface Morphology}

Figure 1a-f present 2D (Figure 1a-c) and 3D (Figure 1d-f) AFM images of 3 selected $\mathrm{SiC}$ films showing the influence of the argon pressure on the morphology of their surfaces. These images reveal that the deposited SiC films grow in grain/columnar mode and have compact structures. As can be seen, uneven surface grains are observed, and their size and, consequently, the root mean square roughness $\left(\mathrm{R}_{\mathrm{RMS}}\right)$, gradually increases as the gas pressure increases. The gas scattering effect explains well this behavior: the number of gasphase collisions in the path from the targets to the substrate increases with the gas pressure, leading to a decrease in the mean free path. This scattering effect leads to a decrease in the kinetic energy of the sputtered particles, increasing their angular distribution. This 
effect determines the reduction of the deposition rate. The increased angular distribution enhances the shadowing effect, while the reduced kinetic energy lowers the mobility of the ad-atoms on the surface of the growing film [23]. According to the relationship between the process pressure and kinetic energy of the sputtered particles, under low gas pressure, the sputtering process is mainly ballistic. Consequently, the sputtered particles can reach the substrate with few or no collisions in the gas phase, and due to sufficient energy diffusion and migration, they can fill the voids in the film's volume, leading to smooth thin films.
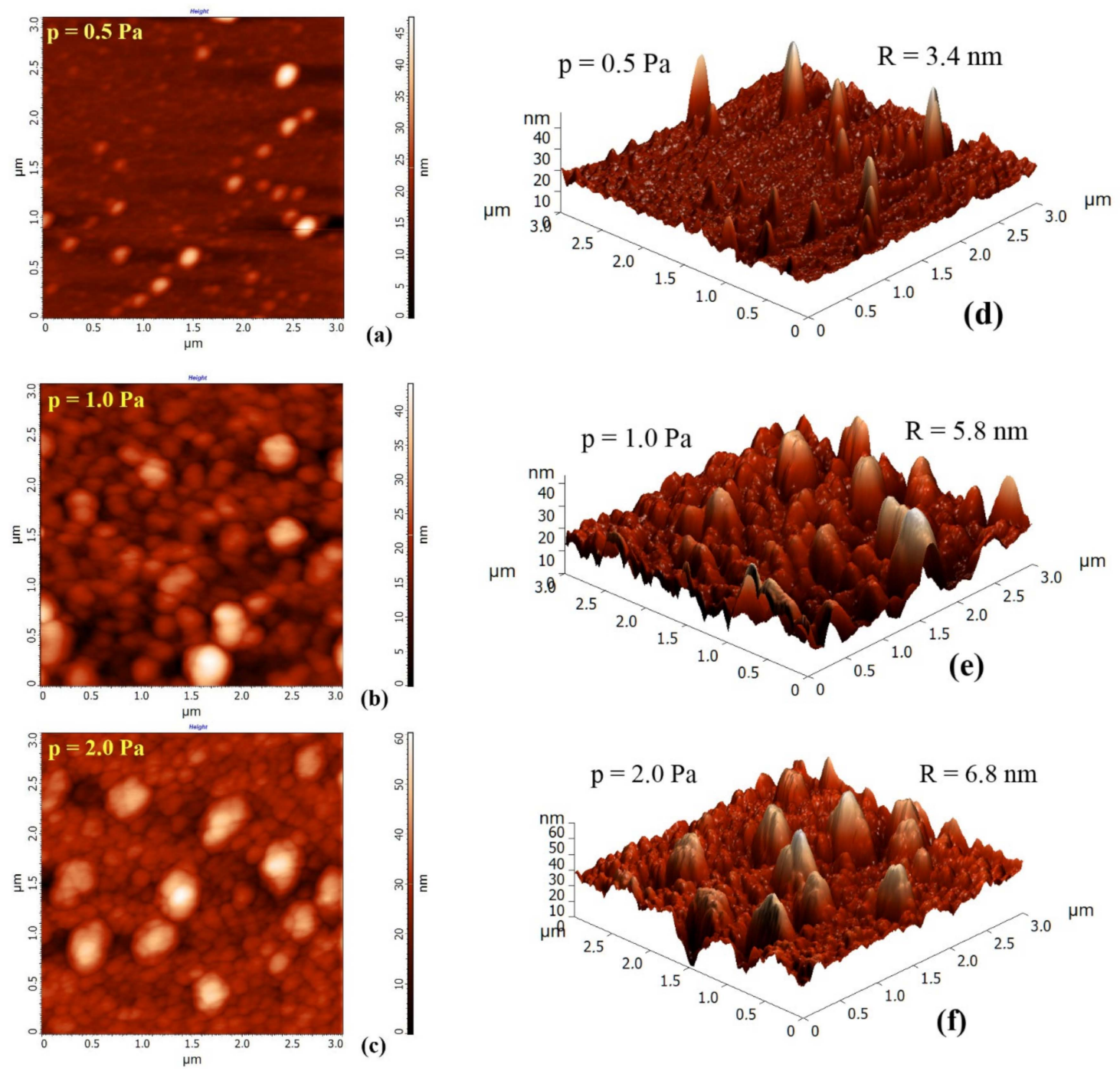

Figure 1. AFM images in $2 \mathrm{D}$ and $3 \mathrm{D}$ showing the surface morphology of $\mathrm{SiC}$ films deposited under 3 different process gas pressures: 0.5, 1.0, and 2.0 Pa, respectively: $2 \mathrm{D}$ images (a) $\mathrm{p}=0.5 \mathrm{~Pa}$, (b) $\mathrm{p}=1.0 \mathrm{~Pa},(\mathbf{c}) \mathrm{p}=2.0 \mathrm{~Pa}$, and 3D images (d) $\mathrm{p}=0.5 \mathrm{~Pa},(\mathbf{e}) \mathrm{p}=1.0 \mathrm{~Pa},(\mathbf{f}) \mathrm{p}=2.0 \mathrm{~Pa}$.

\subsection{Chemical Composition}

The chemical composition of the deposited $\mathrm{SiC}$ thin films was accurately measured by EDX. Table 1 (previously presented) summarizes the atomic percentages of silicon and carbon measured on each $\mathrm{SiC}$ thin film deposited under different working gas pressure conditions. EDX results clearly show that all the deposited $\mathrm{SiC}$ thin films are near stoichiometric.

\subsection{Structural Properties}

\subsubsection{Raman Spectroscopy}

Raman scattering was used to investigate the influence of the working gas pressure on the chemical bonding configuration of silicon carbide thin films. Raman spectroscopy is 
a powerful non-destructive characterization tool for silicon carbide due to its capability to identify atomic polar bonds, such as $\mathrm{Si}-\mathrm{Si}, \mathrm{C}-\mathrm{C}$, and $\mathrm{Si}-\mathrm{C}$, as well as $\mathrm{Si}$ and $\mathrm{C}$ clusters embedded in the $\mathrm{SiC}$ thin films. The Raman spectra of the as-deposited $\mathrm{SiC}$ samples were acquired within the $400-1800 \mathrm{~cm}^{-1}$ spectral range.

As shown in Figure 2, the first band, positioned around $480 \mathrm{~cm}^{-1}$, corresponds to the $\mathrm{Si}-\mathrm{Si}$ transverse optical (TO) mode from amorphous $\mathrm{Si}$. A TO mode of nanocrystalline $\mathrm{Si}$ (c-Si) sharp peak appears at $520 \mathrm{~cm}^{-1}$. As the processing gas pressure decreases, the intensity of the c-Si peak increases. The enhanced intensity at lower gas pressure may be due to the increased energy and mobility of ad-atoms (see discussion from Section 3.1). Lattemann et al. [20] showed that the intensity of the c-Si peak steeply increases as the substrate bias increases due to the enhanced energy of the deposited ions. The broad and weak band, which peaked at approximately $790 \mathrm{~cm}^{-1}$, is typical for the TO mode of nanocrystalline $\mathrm{SiC}$, while the band centered at $968 \mathrm{~cm}^{-1}$ belongs to the longitudinal optic (LO) mode of the A1 symmetry of SiC [24]. Nakashima et al. [25] reported a similar feature, and they attributed it to cubic ( $\mathrm{TO}$ mode) and hexagonal ( $\mathrm{LO}$ mode) $\mathrm{SiC}$ polytypes, respectively.

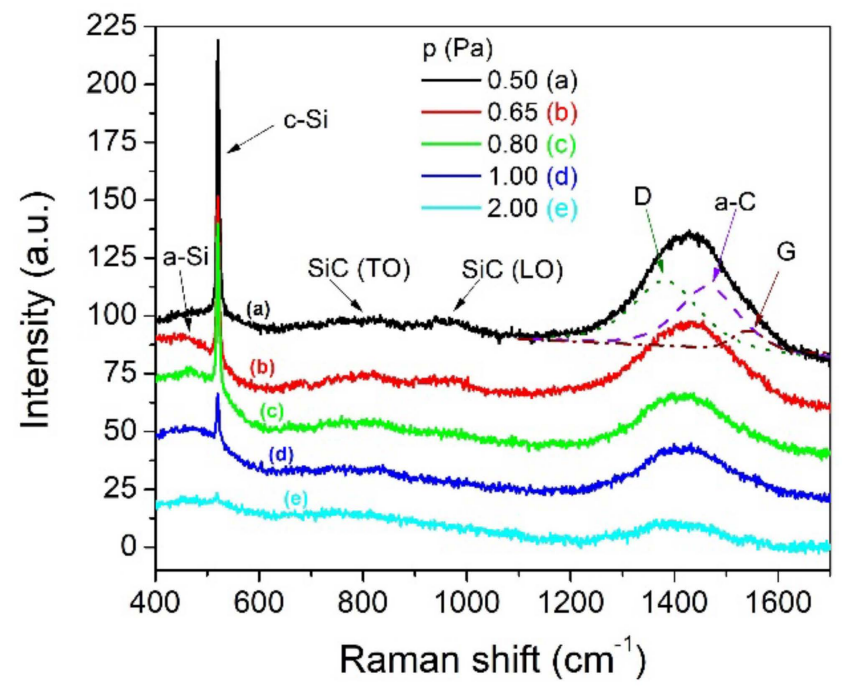

Figure 2. Raman spectra of $\mathrm{SiC}$ thin films deposited on Si substrates using DCMS/HiPIMS cosputtering technique under different process pressures (a) $\mathrm{p}=0.50 \mathrm{~Pa}$, (b) $\mathrm{p}=0.65 \mathrm{~Pa}$, (c) $\mathrm{p}=0.80 \mathrm{~Pa}$, (d) $\mathrm{p}=1.00 \mathrm{~Pa},(\mathrm{e}) \mathrm{p}=2.00 \mathrm{~Pa}$.

The broad band situated between 1200 and $1600 \mathrm{~cm}^{-1}$ is related to $C-C$ vibrational modes. The Gaussian fitting of this broad band reveals 3 peaks: 2 typical peaks of amorphous carbon materials (D peak at $1380 \mathrm{~cm}^{-1}$ and $G$ peak at $1550 \mathrm{~cm}^{-1}$ ) and an a-C peak centered at $1450 \mathrm{~cm}^{-1}$ [26]. The $\mathrm{G}$ peak is directly related to the bond stretching of $\mathrm{sp}^{2}$ sites in both graphitic ring and olefinic chain structures, a common feature of all disordered carbons ( $\mathrm{sp}^{3}$ hybridization), while the $\mathrm{D}$ peak is an indication that the $s p^{2}$ sites are organized only into graphitic rings. DLC (diamond-like carbon) with higher $s p^{3}$ content tends to have more chain structures, which are linked to higher mass density and hardness. As compared to the D peak, the intensity of the G peak is much lower because the $s p^{3}$ coordinated amorphous carbon is hard to directly observe in visible Raman [27]. The band detected at $1450 \mathrm{~cm}^{-1}$ corresponds to a precursor phase of the tetrahedrally bonded carbon, and it is a sign of partial crystallization of carbon clusters [28].

Even if the $\mathrm{SiC}$ coatings are near stoichiometric, the relative intensity of the $\mathrm{Si}-\mathrm{C}$ bands is very low, and the carbon bands dominate the Raman spectra. The much higher scattering cross-section and absorption coefficient of the $\mathrm{C}-\mathrm{C}$ bonds as compared to the $\mathrm{Si}-\mathrm{C}$ bonds seems to be the main reason for this behavior [29]. By decreasing the gas pressure, the intensities of $\mathrm{C}, \mathrm{SiC}$, and c-Si bands increase, highlighting the enhancement of the density of bonding states and the improvement of short-range order. The Raman spectra of coatings deposited at 0.5, 0.65 and $0.8 \mathrm{~Pa}$ look the same as those reported by Craciun et al. [30] for 
near stoichiometric and nanocrystalline $\mathrm{SiC}$ layers deposited by pulsed laser deposition at a nominal substrate temperature of $1000^{\circ} \mathrm{C}$.

\subsubsection{X-ray Diffractometry}

The structure of the magnetron-sputtered silicon carbide thin films was investigated by carrying out X-ray diffraction measurements. Figure 3 displays XRD patterns for the as-deposited $\mathrm{SiC}$ thin films. Analyzing these diffraction patterns, it can be seen that the samples deposited with 1 and $2 \mathrm{~Pa}$ argon pressure are amorphous, while the samples deposited with $0.50,0.65$, and $0.80 \mathrm{~Pa}$ argon pressure are composed of a mixture of hexagonal, cubic and rhombohedral $\mathrm{SiC}$ phases.

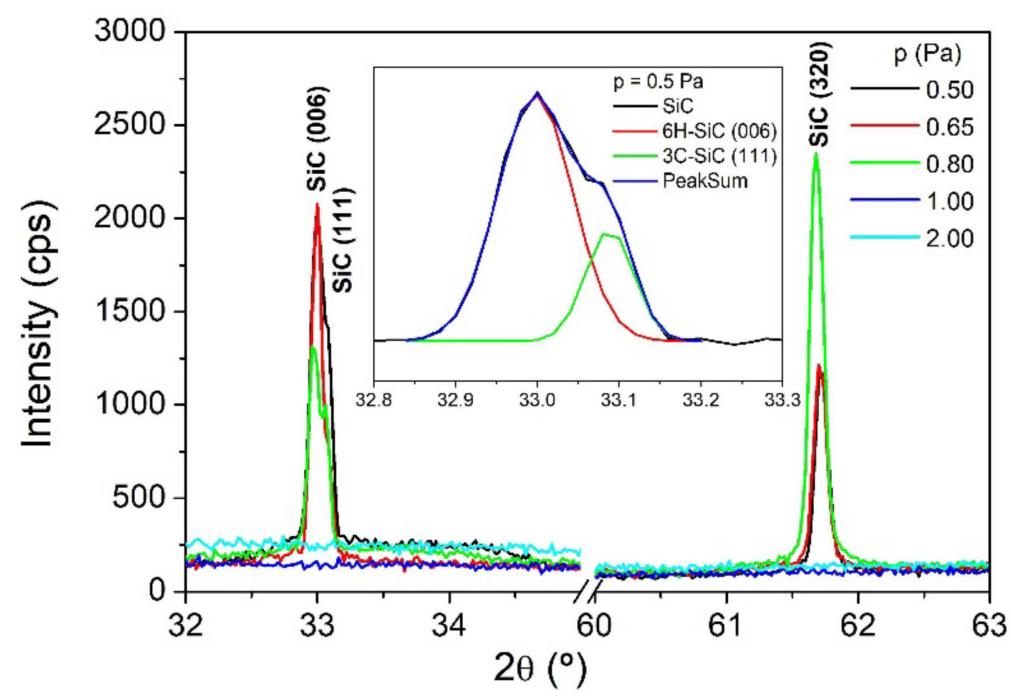

Figure 3. XRD patterns of $\mathrm{SiC}$ thin films deposited under different gas pressures. The inserted graph displays the deconvolution of the $\operatorname{SiC}$ peak $\left(2 \theta=33^{\circ}\right)$ observed for the sample deposited at $0.5 \mathrm{~Pa}$.

A nanocrystalline structure (but with different phases) was recently reported by Galvão et al. [19] for SiC films deposited by HiPIMS at ambient temperature. The XRD results reported in this paper are more consistent with those reported by Craciun [30] and Keffous [31]. The peak positioned at $33.0^{\circ}$ corresponds to the hexagonal phase $6 \mathrm{H}-\mathrm{SiC}(006)$ and cubic phase 3C-SiC (111) [30], while the peak from $61.7^{\circ}$ is assigned to the rhombohedral SiC (320) phase [31]. As the gas pressure increases, the films' structure changes from a hexagonal-preferential orientation to a rhombohedral-preferential orientation.

The XRD results are well correlated with Raman data, which show a gradual decrease of $\mathrm{SiC}$ bands, corresponding to hexagonal and cubic phases, by increasing the Ar pressure in the deposition chamber. The intense energetic ion bombardment during the magnetron sputtering of the Si target can contribute to a nano-size refinement of the crystallites by means of re-nucleation, and it can also explain the lack of other significant $6 \mathrm{H}-\mathrm{SiC}$ peaks. XRD data highlight the fact that ion bombardment (controlled by the working gas pressure) can modify the growth mechanism of the $\mathrm{SiC}$ thin films, and it can also strongly influence their crystalline structure and degree of crystallinity. By decreasing the gas pressure, due to a larger mean free path, the sputtered particles preserve their intrinsic energy, which in turn results in improved ad-atom mobility and enhanced atomic short-range order.

\subsection{Mechanical Properties}

The process pressure has a significant influence on the mechanical and tribological performance of the deposited $\mathrm{SiC}$ thin films. Comparative data concerning the determined values of the mechanical and tribological parameters (hardness, Young's modulus, critical adhesion loads) of $\mathrm{SiC}$ films deposited on Si substrates at ambient temperature with different values of the working gas pressure are listed in Table 2. 
Table 2. Values for hardness (H), Young's modulus (E), H/E and $\mathrm{H}^{3} / \mathrm{E}^{2}$ ratios, and critical adhesion loads (LC) for $\mathrm{SiC}$ films deposited on silicon substrates using different process pressures.

\begin{tabular}{cccccccc}
\hline Sample & $\mathbf{p}(\mathbf{P a})$ & $\mathbf{H}(\mathbf{G P a})$ & $\mathbf{E}(\mathbf{G P a})$ & $\mathbf{H} / \mathbf{E}$ & $\mathbf{H}^{\mathbf{3}} / \mathbf{E}^{\mathbf{2}}$ & $\mathbf{L C}_{\mathbf{2}} \mathbf{( N )}$ & $\mathbf{L C} \mathbf{3}(\mathbf{N})$ \\
\hline SiC_1 & 0.50 & $20.7 \pm 1.4$ & $240 \pm 11$ & $0.086 \pm 0.010$ & $0.154 \pm 0.045$ & $2.13 \pm 0.31$ & $3.85 \pm 0.27$ \\
$\mathrm{SiC}$ 2 & 0.65 & $16.5 \pm 0.8$ & $200 \pm 17$ & $0.082 \pm 0.011$ & $0.112 \pm 0.035$ & $1.44 \pm 0.04$ & $1.85 \pm 0.11$ \\
$\mathrm{SiC}$ 3 & 0.80 & $15.7 \pm 0.3$ & $229 \pm 27$ & $0.069 \pm 0.009$ & $0.075 \pm 0.022$ & $1.07 \pm 0.20$ & $1.41 \pm 0.23$ \\
$\mathrm{SiC}$ 4 & 1.00 & $10.4 \pm 0.7$ & $156 \pm 24$ & $0.066 \pm 0.015$ & $0.046 \pm 0.023$ & $0.46 \pm 0.05$ & $1.19 \pm 0.16$ \\
SiC_5 & 2.00 & $8.2 \pm 0.8$ & $106 \pm 11$ & $0.077 \pm 0.016$ & $0.049 \pm 0.025$ & $0.75 \pm 0.06$ & $1.55 \pm 0.23$ \\
\hline
\end{tabular}

When the argon pressure is increased from 0.5 to $2.0 \mathrm{~Pa}$, the hardness and Young's modulus gradually decrease from 20.7 to $8.2 \mathrm{GPa}(\mathrm{H})$ and from 240 to $106 \mathrm{GPa}(\mathrm{E})$, respectively (see Figure 4). This behavior can be associated with the structural evolution of the films, their atomic-range order and the $\mathrm{Si}-\mathrm{C}$ bond density. This change is also influenced by the creation of numerous growth defects (micro-voids, dangling bonds and structural disorders, such as $\mathrm{Si}$ or $\mathrm{C}$ clusters embedded in the $\mathrm{SiC}$ films). In the case of completely amorphous $\mathrm{SiC}$ films formed under high gas pressure ( $2 \mathrm{~Pa}$ ), the low hardness value may be due to their low densification degree. The increase of the gas pressure results in reduced kinetic energy and mobility of the ad-atoms on the surface of the growing film and, consequently, in a less dense structure and a lower short-range order.

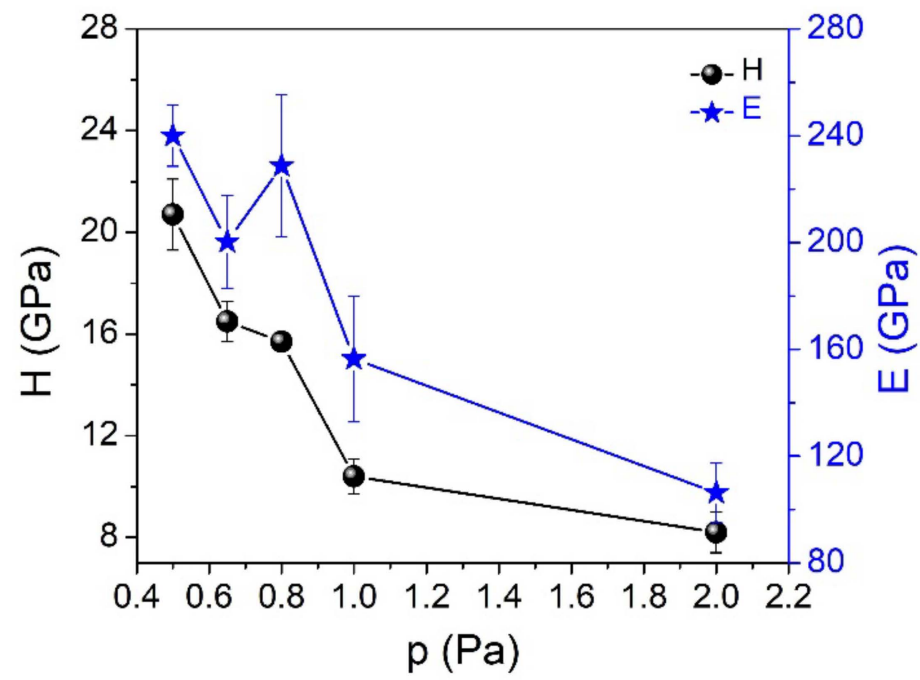

Figure 4. The variation of hardness and Young's modulus of SiC thin films as a function of the process pressure.

Both hardness and Young's modulus can be significantly enhanced by increasing the deposition temperature, which leads to an improvement in the short-range order and partial crystallization of the film [32]. However, an analysis of the influence of this deposition parameter was beyond the scope of the present work. On the other hand, the hardness and Young's modulus of the SiC films are strongly related to their Si-C bond density. El Khakani [33] showed that $\mathrm{H}$ and $\mathrm{E}$ values are strongly related to the $\mathrm{Si}-\mathrm{C}$ bond density in $\mathrm{SiC}$ films. An increase in the $\mathrm{Si}-\mathrm{C}$ bond density results in a strengthening of atomic bonds and, consequently, in an improvement in their mechanical and tribological performance.

The hardness and Young's modulus have a significant influence on the wear behavior, for instance. The resistance to elastic deformation (elastic strain to failure), represented by the $\mathrm{H} / \mathrm{E}$ ratio, has been used to predict the wear resistance of a material $[34,35]$. With the exception of the case of the sample produced under 2.0 $\mathrm{Pa}$ argon pressure, the $\mathrm{H} / \mathrm{E}$ ratio increases when the gas pressure decreases (Figure 5), especially when the polycrystalline $\mathrm{SiC}$ phase starts to be formed in the amorphous matrix (see XRD and Raman results). In other words, the hardness enhancement is probably due not only to the Young's modulus 
enhancement, but also due to the formation of specific nanostructures (crystalline phases) which prevent the plastic deformation of the coating. The nano-size refinement of the crystallites by re-nucleation during the deposition process prevents pronounced growth of the grains, as can be clearly seen from the AFM images.

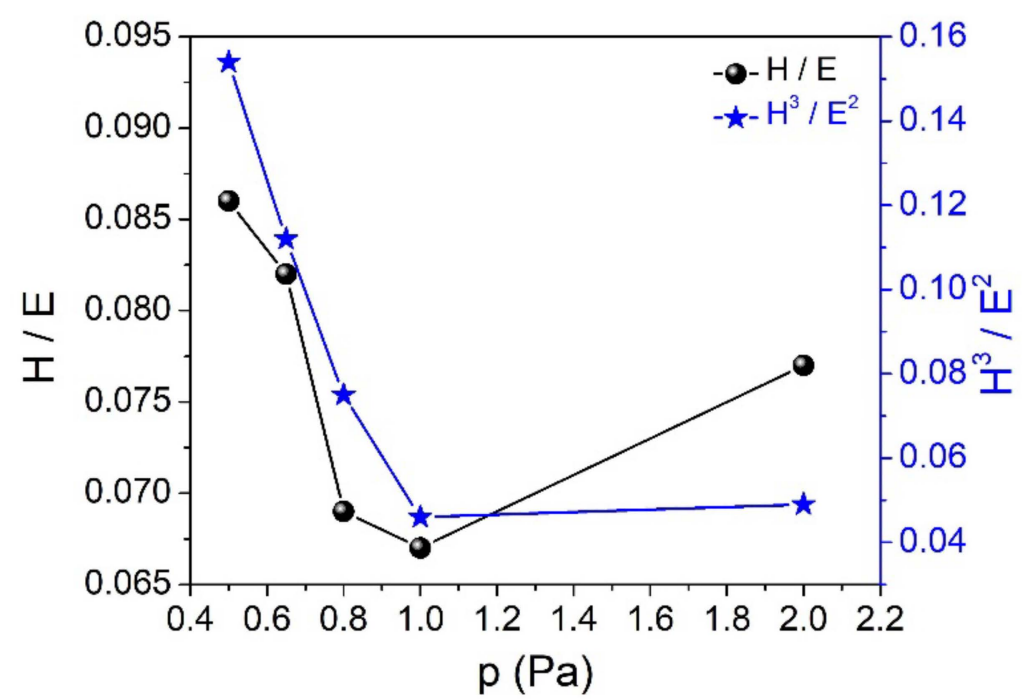

Figure 5. The variation of $\mathrm{H} / \mathrm{E}$ and $\mathrm{H}^{3} / \mathrm{E}^{2}$ ratios of $\mathrm{SiC}$ thin films as a function of the process pressure.

The $\mathrm{H}^{3} / \mathrm{E}^{2}$ ratio helps to estimate what happens in terms of dissipation of energy when the film suffers plastic deformation under a certain load [36]. The obtained results match the results of the $\mathrm{H} / \mathrm{E}$ ratio. The films with higher resistance to elastic deformation, produced under $\mathrm{p}=2.0 \mathrm{~Pa}$ argon pressure, are those that dissipate more energy when plastic deformation occurs. The $\mathrm{H} / \mathrm{E}^{2}$ ratio gives information about the resistance of the material to permanent damage [37]. The variation of this ratio as a function of the deposition pressure (not shown here) is the opposite of the other two ratios. Those films exhibiting lower resistance to elastic deformation are those that may have higher resistance to permanent damage, according to these ratios.

Generally, the produced SiC films exhibited good cohesion, since no cohesive failures (cracks in the coatings) were detected at the beginning of the scratch tests prior to adhesive failure. Figure 6 presents optical micrographs of different stages $\left(\mathrm{LC}_{2}\right.$-left micrograph column, and $\mathrm{LC}_{3}$ —right micrograph column) showing the dynamics of the SiC film-Si substrate system failure and the impact of the working gas pressure on the coating/substrate interfacial behavior.

The variation of both critical adhesion loads, $\mathrm{LC}_{2}$ and $\mathrm{LC}_{3}$, when the working gas pressure was increased from 0.5 to $2.0 \mathrm{~Pa}$, is in good agreement with the trend observed for $\mathrm{H} / \mathrm{E}$ and $\mathrm{H}^{3} / \mathrm{E}^{2}$ ratios, especially for the 0.5-1.0 Pa region (Figures 5 and 7). Increasing the gas pressure from 0.5 to $2.0 \mathrm{~Pa}$, the first adhesive failure $\left(\mathrm{LC}_{2}\right)$ varies from 2.13 to $0.75 \mathrm{~N}$, reaching its minimum value $(0.46 \mathrm{~N})$ at $1.0 \mathrm{~Pa}$ Ar pressure (see Table 2 and Figure 7$)$. The slight increase of $\mathrm{LC}_{2}$ value in the 1.0-2.0 Pa region could be due to an increase in the resistance to permanent damage which, as we mentioned before, was found to have an opposite trend to the $\mathrm{H} / \mathrm{E}$ and $\mathrm{H}^{3} / \mathrm{E}^{2}$ ratios. In general, a better wear behavior is attributed not only to hardness itself, but rather to the $\mathrm{H} / \mathrm{E}$ ratio [34]. In this work, when the working gas pressure is increased from 0.5 to $2.0 \mathrm{~Pa}$, the $\mathrm{H} / \mathrm{E}$ value varies from 0.086 to 0.077 , showing a minimum of 0.066 for the samples deposited under $1.0 \mathrm{~Pa}$ Ar pressure.

The internal stress caused by the large lattice mismatch $(20 \%)$ between the $\mathrm{SiC}$ coatings and $\mathrm{Si}$ substrates and different thermal expansion coefficient $(8 \%)$ may be a potential reason for the relatively low LC values found for the deposited SiC films. It should be mentioned that the coatings presented in this work were obtained without any substrate treatments (interlayer, etching, ion implantation, biasing, heating, annealing). Usually, the adhesion of a film on a substrate may be improved if one of these treatments is performed. The use of 
interlayers can improve the film's adhesion due to reduced thermal stress between $\mathrm{SiC}$ and Si materials [38].

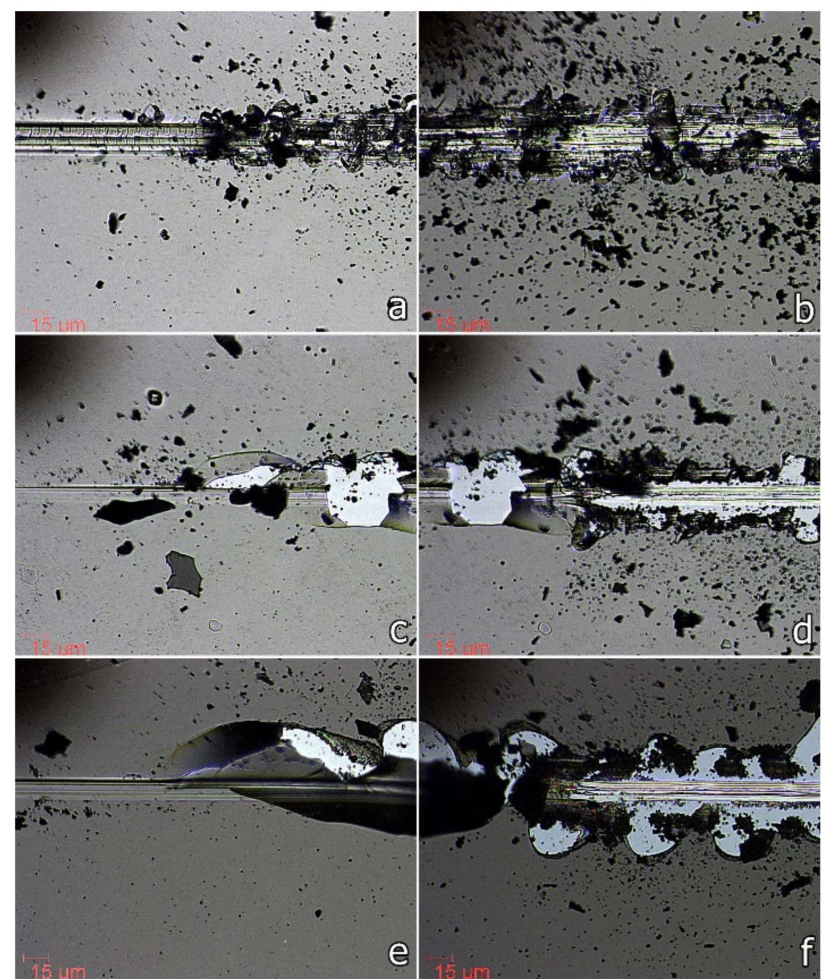

Figure 6. Optical micrographs of scratch tracks showing different stages of material failure (LC2adhesive failure-left, and $\mathrm{LC}_{3}$ - delamination failure-right) for SiC thin films deposited by DCMS/HiPIMS co-sputtering technique on silicon substrates under different working gas pressures: LC2-(a) $\mathrm{p}=0.5 \mathrm{~Pa}$, (c) $\mathrm{p}=1.0 \mathrm{~Pa},(\mathbf{e}) \mathrm{p}=2.0 \mathrm{~Pa}$; LC3-(b) $\mathrm{p}=0.5 \mathrm{~Pa}$, (d) $\mathrm{p}=1.0 \mathrm{~Pa},(\mathbf{f}) \mathrm{p}=2.0 \mathrm{~Pa}$.

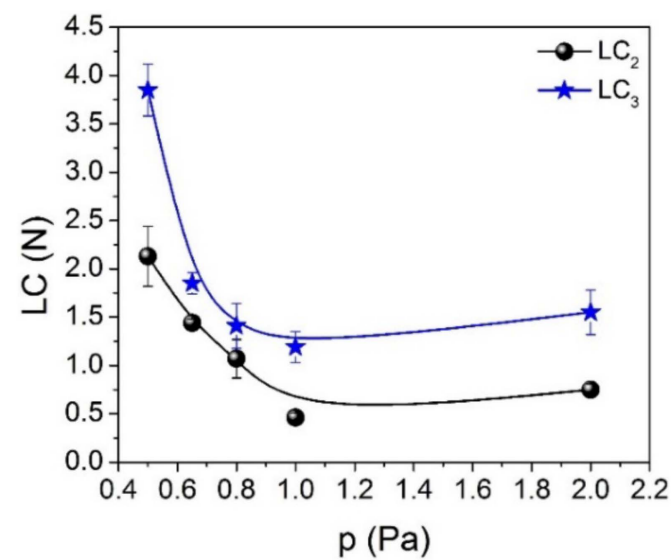

Figure 7. The variation of critical adhesion loads $\left(\mathrm{LC}_{2}\right.$-adhesive failure, and $\mathrm{LC}_{3}$-delamination failure) as a function of the working pressure for $\mathrm{SiC}$ thin films deposited by the DCMS/HiPIMS co-sputtering technique on silicon substrates.

Figure 8 presents the variation of the friction coefficient as a function of the number of passes for the lowest and highest-pressure samples, namely 0.5 Pa and 2.0 Pa and images representing characteristic wear zones captured after the tests. One can observe that, even if the starting friction coefficient, for the first few passes, has relatively similar values, once the silicon nitride ball passes multiple times on the same wear track, the friction coefficient rises significantly for the $2.0 \mathrm{~Pa}$ sample. 

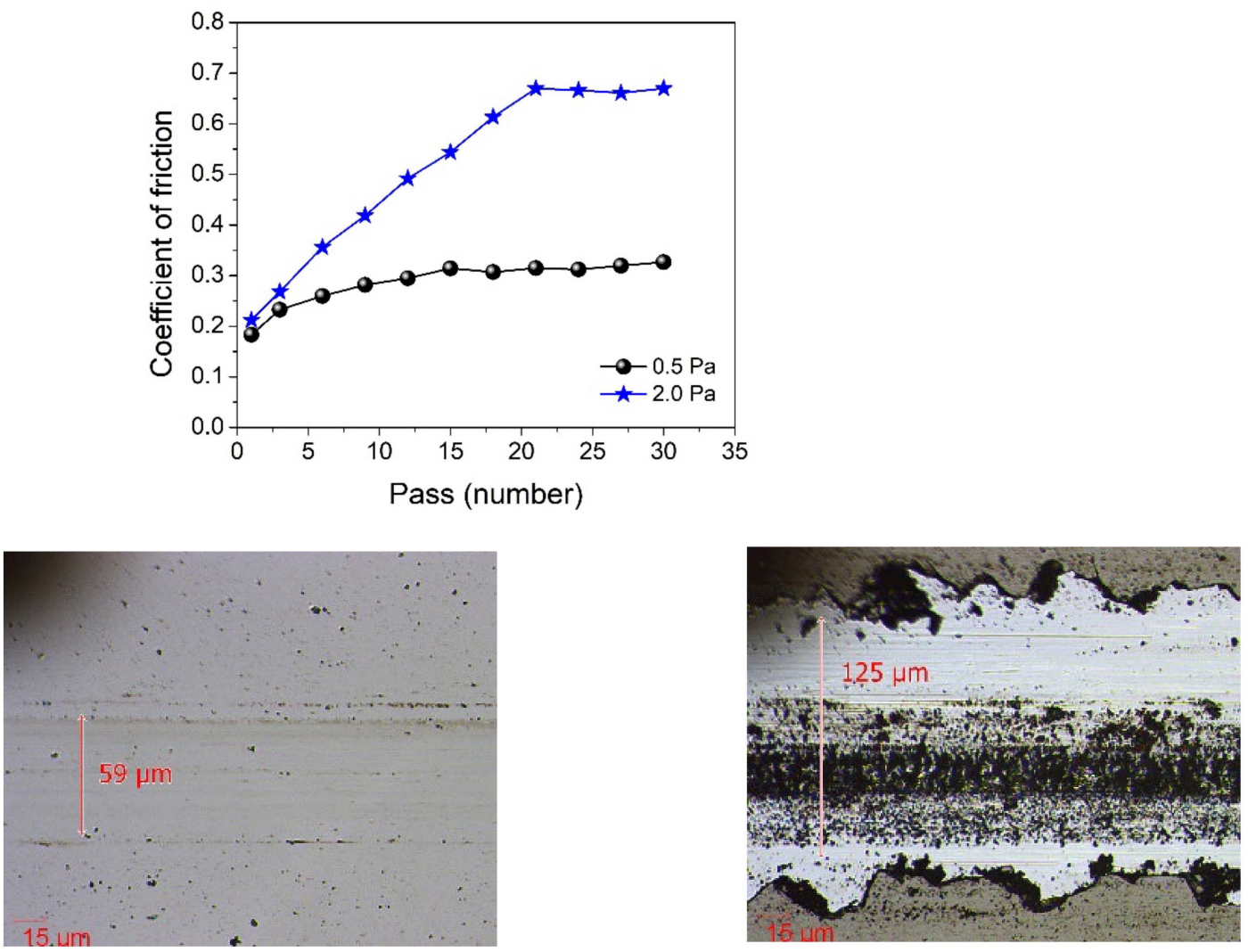

Figure 8. The variation of the friction coefficient as a function of the pass number for the lowest and highest-pressure $\mathrm{SiC}$ samples and images of characteristic wear zones (left image corresponds to the sample deposited under gas pressure of $0.5 \mathrm{~Pa}$, while the right one corresponds to $2.0 \mathrm{~Pa}$ ).

This phenomenon is most likely caused by one or a combination of several factors: (i) significant differences in the $\mathrm{H} / \mathrm{E}$ ratio; (ii) much lower adhesion critical loads for the 2.0 Pa sample (delamination of the coating and presence of wear debris on the wear track); (iii) differences in surface roughness and the film's microstructure.

According to cross-sectional SEM images (Figure 9), a denser and more homogeneous film tends to be formed under lower processing gas pressure. The increase of the process pressure leads to a columnar and more porous structure in the film, which, in turn, results in a decrease of the abrasive wear resistance.
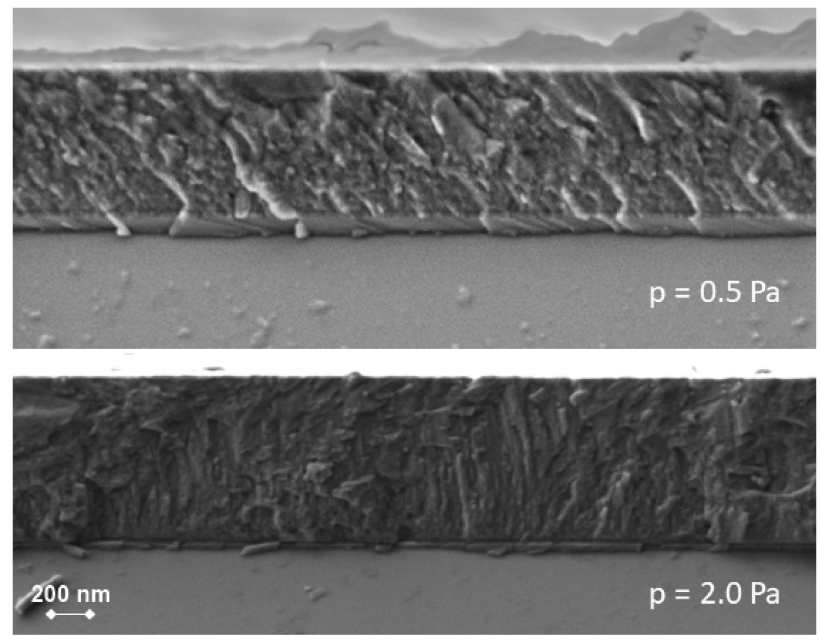

Figure 9. Cross-sectional SEM images of $\mathrm{SiC}$ thin films deposited at 0.5 and $2.0 \mathrm{~Pa}$, respectively. 


\section{Conclusions}

This study showed that both structural and mechanical properties of SiC thin films can be significantly influenced and tailored during DCMS/HiPIMS co-sputtering deposition if the working gas (argon) pressure is varied over a range of 0.5-2.0 Pa. It has also been shown that the DCMS/HiPIMS co-sputtering technique allows the deposition of near stoichiometric and nanocrystalline $\mathrm{SiC}$ thin films without heating or biasing the substrate. The obtained results indicate a strong correlation between films' microstructure and mechanical properties. Decreasing the process pressure leads to low surface roughness, dense structure and an enhancement in the short-range order and bonding states of SiC thin films, resulting in superior mechanical and tribological performance.

Author Contributions: V.T.-conceptualization, methodology, validation, formal analysis, investigation, data curation, writing —original draft preparation, visualization, supervision; E.-L.U.-formal analysis, data curation; D.C.-formal analysis, investigation, data curation, writing-original draft preparation, writing - review and editing, funding acquisition; G.B.-formal analysis, data curation; G.S.--formal analysis, data curation; T.M.-methodology, validation, formal analysis, data curation; I.-L.V.-methodology, validation, formal analysis, investigation, data curation, writing-original draft preparation, writing-review and editing. All authors have read and agreed to the published version of the manuscript.

Funding: This research was funded by UEFISCDI (Research Projects to Stimulate Young Independent Teams) under grant PN-III-P1-1.1-TE-2019-1209.

Institutional Review Board Statement: Not applicable.

Informed Consent Statement: Not applicable.

Data Availability Statement: The data is available on reasonable request from the corresponding author.

Conflicts of Interest: The authors declare no conflict of interest.

\section{References}

1. Scheiffarth, J.H.; Wagner, B.J.; Brennfleck, K.; Huettner, W. Increasing high temperature oxidation and corrosion resistance of graphite and carbon-fiber-reinforced carbon by deposition of a low pressure chemically vapor-deposited silicon carbide coating. Surf. Coat. Technol. 1992, 54, 13-18. [CrossRef]

2. Eriksen, G.F.; Dyrbye, K. Protective coatings in harsh environments. Micromech. Microeng. 1996, 6, 55-57. [CrossRef]

3. Zhao, F.; Islam, M.M.; Huang, C.-F. Photoelectrochemical etching to fabricate single-crystal SiC MEMS for harsh environments. Mater. Lett. 2011, 65, 409-412. [CrossRef]

4. Ricciardi, C.; Fanchini, G.; Mandracci, P. Physical properties of ECR-CVD polycrystalline SiC films for micro-electro-mechanical systems. Diam. Relat. Mater. 2003, 12, 1236-1240. [CrossRef]

5. Ledermann, N.; Baborowski, J.; Muralt, P.; Xantopoulos, N.; Tellenbach, J.-M. Sputtered silicon carbide thin films as protective coating for MEMS applications. Surf. Coat. Technol. 2000, 125, 246-250. [CrossRef]

6. Santavirta, S.; Takagi, M.; Nordsletten, L.; Anttila, A.; Lappalainen, R.; Konttinen, Y.T. Biocompatibility of silicon carbide in colony formation test in vitro. A promising new ceramic THR implant coating material. Arch. Orthop. Traum. Surg. 1998, 118, 89-91. [CrossRef] [PubMed]

7. Seo, J.K.; Ko, K.H.; Choi, W.S.; Park, M.; Lee, J.H.; Yi, J.S. The effect of deposition RF power on the SiC passivation layer synthesized by an RF magnetron sputtering method. J. Cryst. Growth 2011, 326, 183-185. [CrossRef]

8. Stamate, M.D. Strong dependence of IR absorption in a-SiC:H dc magnetron sputtered thin films on $\mathrm{H}_{2}$ partial pressure. Appl. Surf. Sci. 2001, 172, 47-50. [CrossRef]

9. Raynaud, C.; Tournier, D.; Morel, H.; Planson, D. Comparison of high voltage and high temperature performances of wide bandgap semiconductors for vertical power devices. Diam. Relat. Mater. 2010, 19, 1-6. [CrossRef]

10. Bräuer, G.; Szyszka, B.; Vergö, M.; Bandorf, R. Magnetron sputtering-Milestones of 30 years. Vacuum 2010, 84, 1354-1359. [CrossRef]

11. Leal, G.; Campos, T.M.B.; da Silva Sobrinho, A.S.; Pessoa, R.S.; Maciel, H.S.; Massi, M. Characterization of SiC thin films deposited by HiPIMS. Mater. Res. 2014, 17, 472-476. [CrossRef]

12. Velicu, I.-L.; Tiron, V.; Rusu, B.G.; Popa, G. Copper thin films deposited under different power delivery modes and magnetron configurations: A comparative study. Surf. Coat. Technol. 2017, 327, 192-199. [CrossRef]

13. Tiron, V.; Velicu, I.-L.; Cristea, D.; Lupu, N.; Stoian, G.; Munteanu, D. Influence of ion-to-neutral flux ratio on the mechanical and tribological properties of TiN coatings deposited by HiPIMS. Surf. Coat. Technol. 2018, 352, 690-698. [CrossRef] 
14. Tiron, V.; Velicu, I.-L.; Pana, I.; Cristea, D.; Rusu, B.G.; Dinca, P.; Porosnicu, C.; Grigore, E.; Munteanu, D.; Tascu, S. HiPIMS deposition of silicon nitride for solar cell application. Surf. Coat. Technol. 2018, 344, 197-203. [CrossRef]

15. Čapek, J.; Hála, M.; Zabeida, O.; Klemberg-Sapieha, J.E.; Martinu, L. Deposition rate enhancement in HiPIMS without compromising the ionized fraction of the deposition flux. J. Phys. D Appl. Phys. 2013, 46, 205205. [CrossRef]

16. Tiron, V.; Velicu, I.-L.; Porosnicu, C.; Burducea, I.; Dinca, P.; Malinský, P. Tungsten Nitride Coatings Obtained by HiPIMS as Plasma Facing Materials for Fusion Applications. Appl. Surf. Sci. 2017, 416, 878-884. [CrossRef]

17. Dinca, P.; Tiron, V.; Mihaila, I.; Velicu, I.-L.; Porosnicu, C.; Butoi, B.; Velea, A.; Grigore, E.; Costin, C.; Lungu, C.P. Negative ion-induced deuterium retention in mixed W-Al layers co-deposited in dual-HiPIMS. Surf. Coat. Technol. 2019, 363, $273-281$. [CrossRef]

18. Dinca, P.; Porosnicu, C.; Butoi, B.; Jepu, I.; Tiron, V.; Pompilian, O.G.; Burducea, I.; Lungu, C.P.; Velicu, I.-L. Beryllium-Tungsten Study on Mixed Layers obtained by m-HiPIMS/DCMS Techniques in a Deuterium and Nitrogen Reactive Gas Mixture. Surf. Coat. Technol. 2017, 321, 397-402. [CrossRef]

19. Galvão, N.; Guerino, M.; Campos, T.; Grigorov, K.; Fraga, M.; Rodrigues, B.; Pessoa, R.; Camus, J.; Djouadi, M.; Maciel, H. The Influence of AlN Intermediate Layer on the Structural and Chemical Properties of SiC Thin Films Produced by High-Power Impulse Magnetron Sputtering. Micromachines 2019, 10, 202. [CrossRef]

20. Lattemann, M.; Nold, E.; Ulrich, S.; Leiste, H.; Holleck, H. Investigation and characterisation of silicon nitride and silicon carbide thin films. Surf. Coat. Technol. 2003, 174-175, 365-369. [CrossRef]

21. Tiron, V.; Velicu, I.-L.; Matei, T.; Cristea, D.; Cunha, L.; Stoian, G. Ultra-Short Pulse HiPIMS: A Strategy to Suppress Arcing during Reactive Deposition of $\mathrm{SiO}_{2}$ Thin Films with Enhanced Mechanical and Optical Properties. Coatings 2020, 10, 633. [CrossRef]

22. Oliver, W.C.; Pharr, G.M. Measurement of hardness and elastic modulus by instrumented indentation: Advances in understanding and refinements to methodology. J. Mater. Res. 2004, 19, 3-20. [CrossRef]

23. Thornton, J.A. The microstructure of sputter-deposited coatings. J. Vac. Sci. Technol. A 1986, 4, 3059-3065. [CrossRef]

24. Hiroshi, H. Raman scattering characterization on SiC. Microelectron. Eng. 2006, 83, 126-129. [CrossRef]

25. Nakashima, S.; Harima, H. Raman Investigation of SiC Polytypes. Phys. State Solids 1997, 162, 39-64. [CrossRef]

26. Cheng, Y.; Huang, X.; Du, Z.; Xiao, J. Effect of sputtering power on the structure and optical band gap of SiC thin films. Opt. Mater. 2017, 73, 723-728. [CrossRef]

27. Ferrari, A.C.; Kleinsorge, B.; Adamopoulos, G.; Robertson, J.; Milne, W.I.; Stolojan, V.; Brown, L.M.; LiBassi, A.; Tanner, B.K Determination of bonding in amorphous carbons by electron energy loss spectroscopy, Raman scattering and X-ray reflectivity. $J$. Non-Cryst. Solids 2000, 266-269, 765-768. [CrossRef]

28. Ferrari, A.C.; Robertson, J. Interpretation of Raman spectra of disordered and amorphous carbon. Phys. Rev. B 2000, 61, 14095-14107. [CrossRef]

29. Hillel, R.; Maline, M.; Gourbilleau, F.; Nouet, G.; Carles, R.; Mlayah, A. Microstructure of chemically vapour codeposited SiC-TiC-C nanocomposites. Mater. Sci. Eng. A 1993, 168, 183-187. [CrossRef]

30. Craciun, V.; Craciun, D.; Socol, G.; Behdad, S.; Boesl, B.; Himcinschi, C.; Makino, H.; Socol, M.; Simeone, D. Investigations of Ar ion irradiation effects on nanocrystalline SiC thin films. Appl. Surf. Sci. 2016, 374, 339-345. [CrossRef]

31. Keffous, A.; Gabouze, N.; Cheriet, A.; Belkacem, Y.; Boukezzata, A. Investigation of porous silicon carbide as a new material for environmental and optoelectronic applications. Appl. Surf. Sci. 2010, 256, 5629-5639. [CrossRef]

32. Kulikovsky, V.; Vorlíček, V.; Boháč, P.; Stranyánek, M.; Čtvrtlík, R.; Kurdyumov, A.; Jastrabik, L. Hardness and elastic modulus of amorphous and nanocrystalline SiC and Si films. Surf. Coat. Technol. 2008, 202, 1738-1745. [CrossRef]

33. El Khakani, M.A.; Chaker, M.; Jean, A.; Boily, S.; Kieffer, J.C. Hardness and Young's modulus of amorphous a-SiC thin films. J. Mater. Res. 1994, 9, 96-103. [CrossRef]

34. Leyland, A.; Matthews, A. On the significance of the $H / E$ ratio in wear control: A nanocomposite coating approach to optimised tribological behaviour. Wear 2000, 246, 1-11. [CrossRef]

35. Affonso, L.O. Machinery Failure Analysis Handbook—Sustain Your Operations and Maximize Uptime; Gulf Publishing Company: Houston, TX, USA, 2006.

36. Tsui, T.Y.; Pharr, G.M.; Oliver, W.C.; Bhatia, C.S.; White, R.L.; Anders, S.; Anders, A.; Brown, I.G. Nanoindentation and nanoscratching of hard carbon coatings for magnetic discs. MRS Proc. 1995, 383, 383-447. [CrossRef]

37. Joslin, D.L.; Oliver, W.C. A new method for analyzing data from continuous depth-sensing microindentation tests. J. Mater. Res. 1990, 5, 123-126. [CrossRef]

38. Galvão, N.; Vasconcelos, G.; Pessoa, R.; Machado, J.; Guerino, M.; Fraga, M.; Rodrigues, B.; Camus, J.; Djouadi, A.; Maciel, H. A Novel Method of Synthesizing Graphene for Electronic Device Applications. Materials 2018, 11, 1120. [CrossRef] 